\title{
Inter-caste Communication Praxis of Namashudra Caste in West Bengal: A Caste Evidence Study
}

\author{
Kaushik Mandal \\ Research Scholar, CJMC, Visva-Bharati, Santiniketan, West Bengal, India \\ Corresponding author: kaushikm198@gmail.com
}

Received: 21 Sept., 2020

Revised: 26 Nov., 2020

Accepted: 15 Dec., 2020

\begin{abstract}
Caste has developed into a significant part of social identity in Indian culture throughout the decades. Discrimination based on caste has an impact on communication process. After seven decades of independence and affirmative action for improving the socio-economic standing of scheduled caste members in the society, study on the condition with reference to discrimination is urgent. The reason, discrimination creates conflict while goodwill and inter-connect bring cooperation and peaceful co-existence. The study undertaken to understand the Namashudra caste's inter-caste communication dynamism in urban setting and rural setting from perception and experience statements by the caste member critically examined the conflict orientation in interpreting inter-caste relationship dominant in caste scholarship. Here, the researcher tests how far the conflict orientation in scholarship holds true for these localities by utilising the perception frame of Namashudra caste people who came in contact with other castes of higher ranks in their own locality. The conclusion, based on field survey among the caste members shows that inter-connect between different castes are on increase.
\end{abstract}

Keywords: Caste, Inter-caste communication, Conflict, Namashudra, Peace, Inter-connect, Inter-interest

In the Indian trans-generational social framework, the caste system is the reality of social organization. By birth, every Hindu individual represents a particular caste. While there are many commonalities among castes. Each caste has its own set of norms, rituals,celebrations,ideals and skills that bind caste members together.

It has been interpreted in a variety of ways that address the co-operative and antagonistic interrelationships between distinct caste groupings. Human endeavor for finding out and continuing with occupation of sustenance and growth at the individual and family level in one generation and through generations passes through neighbourhood, workplace and society at large in search of networking for resource mobilization, instrumentation and exchange for value. Caste system gradually developed as an occupational network where every occupational group required the other. Interaction and exchange are at the core of such networked society.

People from many communities make up the Indian social structure. These individuals in society are divided into many categories. Each homogeneous group creates a unique and intricate caste. In India's social structure, there are hundreds of caste groupings. These caste categories are further subdivided into sub-castes. Each caste group has

\footnotetext{
How to cite this article: Mandal, K. (2020). Inter-caste Communication Praxis of Namashudra Caste in West Bengal: A Caste Evidence Study. Int. J. Peace, Edu. Dev., 8(02): 69-79.

Source of Support: None; Conflict of Interest: None

(9) 9
} 
certain norms to adhere to, which defines their relationship with other castes. Such relationships are often assumed by many scholars as antagonistic, which may or may not be generalized.

Among caste groupings, social mobility implies struggle and cooperation both. The conflict is caused by social, economic, and political issues, as well as the desire of various caste groups to rise to the same level in society as the others. These disputes produced an unbreakable bond between caste members, resulting in long-standing caste stereotypes.

Though reciprocal bonding among these caste groups is an integral part of Indian society, different ties between caste groups promote distinct communication patterns. Communication is crucial in reaching out to all members of society and assisting them in contributing to socio-economic progress. Loho Choudhury (2015) explained Communication as an act of expression "for bringing human beings at same level of understanding about various phenomena, i.e., reaching Sadharanikaran utilizing mood, emotion and expression into foreplay."

Discrimination based on caste has an impact on communication process. After seven decades of independence and affirmative action for improving socio-economic standing of scheduled caste members in the society, study on the condition with reference to discrimination is urgent. The reason, discrimination creates conflict while goodwill and inter-connect bring cooperation and peaceful coexistence.

This study has made a step in that direction by evaluating the phenomenon of intra-caste communication amongst caste members by selecting a politically, economically, and culturally influential caste from the caste categories to comprehend communication phenomena between castes. This research aims better to comprehend the caste hierarchy's inter-caste communication scenario.

\section{Caste and communication}

The caste system provides groups with a distinct type of social life, and hence it may be viewed as a structural category for analyzing the communication process among them. Within and outside the caste, communication socializes and exposes people to varied news, views, values, opportunities etc.

Communication is critical for reaching out to one and all in family, neighbourhood, entire settlement, work place and society at large. Every person in Indian society has a distinct caste identity, even within a family of inter-caste marriage. During their discourse, caste members share information on a variety of topics. Individuals can become more informed, overcome ignorance, and achieve economic and social well-being through using communication. People become more conscious as a result of interaction within caste members and exposure to preferred media. There is a vacuum between the germination of knowledge and its application in our social lives; good communications fills the gap of information and maintain a proper equilibrium in our socio-economic lives.

According to Loho Choudhury (2011), "Communication should have a development value. In every development program, communicating the program through participants should be one motto... to eliminate information poverty, communication process has the responsibility of absorbing relevant up-to-date information to produce and share proper message...Communication process must make communities realize their relevance, interdependence, and interaction with the macro society and country to ensure that isolated isles of prosperity, which are mutually exclusive are not created."

The essence of social interaction is communication. To exchange ideas, people communicate with other people, units, or entities. It only happens when a person wants to share his or her feelings with others. 'Commonness' is a psychological term that can be used to describe this issue. One mind's thoughts cannot be transferred to other's senses to develop a response unless there is a shared understanding. Mutual understanding is the foundation of effective communication.

The exchange of social-cultural-economic-politicalspiritual thought and action among diverse castes 
established socio-religious relationships among them, splitting them into sub-castes initially with development of different occupational activities based on human needs-both individual and collective. Individuals' thoughts are differentiated through the establishment of unique rites and customs between caste groupings.

The reality of disparities in resource ownership is reflected in caste practices and rituals too, and varies within the same caste residing in different places. It is often found that a caste is dominant in some areas while dominated in other areas. People of various castes have unequal access to valuable resources such as wealth and power. There are limitations on interactions and behaviour with people from another social status (Sekhon, 2000).

\section{Ethnographic of Namashudra caste}

The Namashudra group is a traditional farming group in India's eastern region. They lived in Faridpur, Bakarganj, Khulna, Mymensingh, Dacca, and Jessore in Bangladesh. The name 'Chandal' was first recorded in the 1901 census but all Namashudrasdo not belong to Chandal identity. Namashudra is the highest-ranking scheduled caste in the Hindu community. Namashudra constitutes the majority of society in India's eastern region. They are in India, Bangladesh and Nepal.

There are still substantial numbers of Namashudra population in Bangladesh. Those who had arrived in India as refugees due to partition in 1947 and subsequent tortured in East Pakistan. As the poor, homeless, and destitute tried to make a living on others' firms, occupational avocations and whatever work they could avail going beyond their traditional work. Till now, good number of Namasudras crossed over the border due to uncertainty of life on the other side of the border. They are a socioeconomically backward class that was classified as a scheduled caste in India in 1950.

\section{Habitation}

The Namashudra community in West Bengal is concentrated in Mednipur, the South 24 Parganas, the North 24 Parganas, Burdwan, the southern area of Kolkata, and in the Howrah district. They are also found in Assam, Tripura, Odissa, and other states in India, and are now widely dispersed.

Apart from India, the Namashudra people are concentrated in the Bangladeshi districts of Jassore, Barisal, Moymonsingha, Noyakhali, and Chattagram.

\section{Population}

In India, the Namasudra caste is primarily found in West Bengal, Odissa, Tripura and Assam, with smaller populations in other states. Namasudra is the second-largest community in West Bengal, behind Rajbanshi, in terms of population.

\begin{tabular}{cc}
\hline Census year & $\begin{array}{c}\text { Total population of Namashudra } \\
\text { in West Bengal }\end{array}$ \\
\hline 1872 & 201,745 \\
1901 & 174,888 \\
2001 & 3212,393 \\
2011 & 3503,782 \\
\hline
\end{tabular}

Source: Census report of India.

\section{Occupation}

Agriculture is the most important source of income for the Namasudra people. Some of them worked in woodwork, boat building, musical instrument manufacturing, and even in the import-export sector. Many of them work for the government or in the business sector.

\section{LITERATURE REVIEW}

Dutta (1930) did a thorough investigation into caste. He chronicled the evolution of caste and caste rules from the early Vedic period to the present day in his work.

In his work, Weber (1958) emphasizes the Hindu social system's religious ideas. Weber's research of Indian society, the Hindu social order, and religion revealed a single root of caste and a high degree of present relevance. He gave a brief overview of Hinduism's spread and highlighted Hindu doctrines and rituals.

Majumder (1958) depicted the interdependence of the peoples of a multi-caste hamlet, Mohana, in his 
extensive study of "Caste and Communication in an Indian Village." He studied inter-caste connections in the context of numerous traditional village events such as birth, marriage, death, devotional singing and telling, and so on. He studied the socioeconomic interrelationships of various castes and the tension between high and lower castes.

Surajit Sinha (1968) defined the caste system as an organization of people from various social classes who are coordinated in a hereditary division of labour. The function of traditional forms of communication, such as folk media, is hinted at in socio-cultural integration.

The caste system was defined by M.N. Srinivas (1977) as a hereditary and endogamous group with a limited and historical link with their traditional occupations. He also said that the caste was split up into different endogamous sub-castes.

In his article, Satyanarayan (1993) critically examined the interplay between the caste system, landlord power, and agrarian social structure in India's south-east.

Bandyopadhyay's (2004) study of caste in Bengal concentrated on the social and political situation of modern Bengal. The author had shed light on the Namashudras, Bengal's second largest Hindu caste, and its socio-political mobilization.

Tanabe (2006) focused his research on identifying an individual's identity and caste ties in contemporary rural Odissa. He spoke about the caste-based exchanges in the ceremonial domain that persisted thanks to the locals' initiative.

\section{Research methodology}

This study is focused on describing the phenomenon of inter-caste communication through evidences. It seeks to bring to light the interaction, cooperation and conflict among members of different castes. In accordance with the study's objective, the researcher put the phenomenon into a specific category to collect the appropriate data. The phenomenon which is described below through attributes was selected to justify the study's objective. For each attribute, the opinion of the respondents catches perceptional variance between peaceful behaviour and conflict behaviour.

Intrenalising peace and progressing with peaceboth are limited by chances of wisdom-knowledgebehaviour linkage at every level (Loha Choudhury, 2020). Peaceful behaviour represents the sense of inter-connect and inter-interest which reflects in communication. Any disturbance to the same is conflict, reflected in agitational behaviour and negative opinion formed due to prolonged experience of communicating with others. Every non-parametric variable i.e. each attribute selected to represent the phenomenon, being measured between perception of inter-connect and interinterest, and conflictional perception about equal human dignity is put into action considering this perspective.

1. Treatment received from other caste people

2. Interaction with other caste people

3. Respect from other caste people in conversation

4. Quality Listening during interaction by other caste people

5. Relationship with other caste people

6. Namashudra Home Visit by Other Caste Members

7. Inviting other caste people

8. Participation status in family occasions of other caste people

9. Inter-caste sitting and dining

\section{Sample size of the study}

The sample was collected from both rural and urban areas in North 24 Parganas, focusing on both the agricultural and non-agricultural persons of the caste. The investigation is using 100 samples. While calculating the sample size, the following parameters were considered:

1. Adults between the ages of 18 and up who belong to Namashudra caste group have been chosen.

2. Namasudra caste populations, made up of about 50\% rural and 50\% urban dwellers are picked. 


\section{Sampling technique}

Snowball sampling procedures were used in the current study since Namashudra people are widely dispersed throughout the state and even outside of the state.

\section{Research Method}

The following method has been employed for both quantitative and qualitative data collection:

\section{Interview engaging close and open-ended question schedule}

Individual caste members were interviewed in person using an open-ended and closed-ended questioning format. It aided the researcher in comprehending the process of communication between members of different castes.

Inter-caste communication has been studied through personal verbal interviews with members of the caste on many aspects of society were conducted. The information for this study was gathered from both primary and secondary sources. The respondents' primary data was acquired using the interview approach (caste peoples). It was created by conducting face-to-face interviews with the respondents.

\section{Data collection tools}

Data collection tools of the study are as follows:

\section{Interview schedule}

An interview schedule was created using a set of closed and open-ended questions. It aided the researcher in illustrating the research aims and encouraged respondents to keep their opinions to a minimum in order to collect the essential data. Despite the fact that the study's respondents were spread across a broad geographic area, the researcher and the research team individually approached them. Their responses were recorded using the interview schedule.

A set of questions is structured in the first phase, which includes both open-ended and closed-ended questions. Closed-ended questions allow the respondent to select an answer from a list of options by simply ticking it. Respondents were given the flexibility to answer and express themselves fully in open-ended questions.

\section{Research Universe}

Namashudra's urban respondents were chosen from Gobardanga, an old municipal town while rural respondents were selected from Manikhira village. In both areas they live with other Hindu castes such as Brahmin, Kayastha and Vaishyas.

\section{Gobardanga}

It is the oldest municipality town in the block Gaighata in the Bongaon sub-division of West Bengal's North 24 Parganas district, and it is located alongside the Jamuna River. There are 17 wards in the town. This municipality is responsible for over 11502 homes, to which it provides essential services such as electricity, water, and sewerage. According to the 2011 Census of India, it has 45377 people, with 23025 men and 22352 women. In this town, there are 14282 scheduled caste residents, with 7376 males and 6906 females.

\section{Manikhira}

It is a village in Gaighata block's Simulpur gram panchayat. It is located in the North 24 Parganas district of West Bengal, in the Bongaon subdivision. According to the 2011 Census of India, the village has 671 families. It has a population of 2898 people, with 1474 men and 1424 women. In this village, there are 2217 scheduled caste residents, with 1115 males and 1102 females. The majority of the villagers are Namashudra caste members and lowwage employees.

In both the town and the village Namashudras engage in interaction with people of other castes within the locality. Everyone knows the caste identity of the other. So their experience of communication with other castes may be understood well in these settings. 


\section{Justification of the selection of the areas}

Namashudras are residing mainly from the eastern to the western part of India. It is an impossible task to do survey of them. For this study, the urban and rural areas were selected according to the Namashudra population's density to understand how the people of the said caste communicate with other caste people. As the Namashudras are dominant population in these two areas, and they know caste identity of others, their responses about communication with others have a prospect to bring the truth of inter-caste relationship.

\section{Objective}

To understand the Namashudra caste's intercaste communication dynamism in urban setting and rural setting from perception and experience statements by the caste members.

\section{Conceptual Orientation}

To understand inter-caste relationship, conflict objective flows from the conflict orientation in interpreting inter-caste relationship dominant in caste scholarship. Here, the researcher tests how far the conflict orientation in scholarship holds true for these localities by utilising the perception frame of Namashudra caste people who came in contact with other castes of higher ranks in their own locality.

\section{Analysis of Data}

After the collection of data, these were checked for redundancy and rejection, and tools of data analysis analyzed qualified data as per objectives. They were logically represented by bar chart and with percentage table.

\section{Measurement Scale}

In social science research, the measurement of components depends on the objective and orientation of the study. The researcher develops the measurement scale regarding behavioural components or use scales developed by other scientists. In this study, considering these limitations, the researcher screened the behavioural components from peace and conflict representation in the mind of respondents and used the Likert Scale to analyze the data.

\section{Tools of Data Analysis}

The data collected during the survey are fed in SPSS. Here the percentages and bar charts have been applied to facilitate the comparison among non-parametric variables of the study.

\section{Distribution of Respondents}

\section{Findings of the study}

\section{Treatment received from other caste people}

Respondents from the Namashudra caste were asked to describe the treatment they received from other castes during their conversations. Here treatment means how Namashudra feel about them being received by other caste members as reflected in words and gestures. $18 \%$ of respondents stated that all people of other castes regard them as unequal, $27 \%$ said that some people regard them as unequal, $8 \%$ stated that people consider them neutral, $36 \%$ stated that some people regard them as equal. The remaining $11 \%$ stated that all people regard them as similar.

\section{Interaction with other caste people}

Respondents were asked about their interactions with people from other castes in this study. 5\% answered that everyone speaks to them with trepidation. $10 \%$ said that some individuals speak to them with trepidation. 6 percent of respondents claimed that people remain neutral throughout their

Table 1

\begin{tabular}{|c|c|c|c|c|c|c|}
\hline Caste & Area & Numbe & ondents & Place & District & State \\
\hline \multirow{2}{*}{ Namashudra } & Rural & \multirow{2}{*}{100} & 46 & Manikhira & North 24 Parganas & West Benga \\
\hline & Urban & & 54 & Gobardanga & North 24 Parganas & West Benga \\
\hline
\end{tabular}




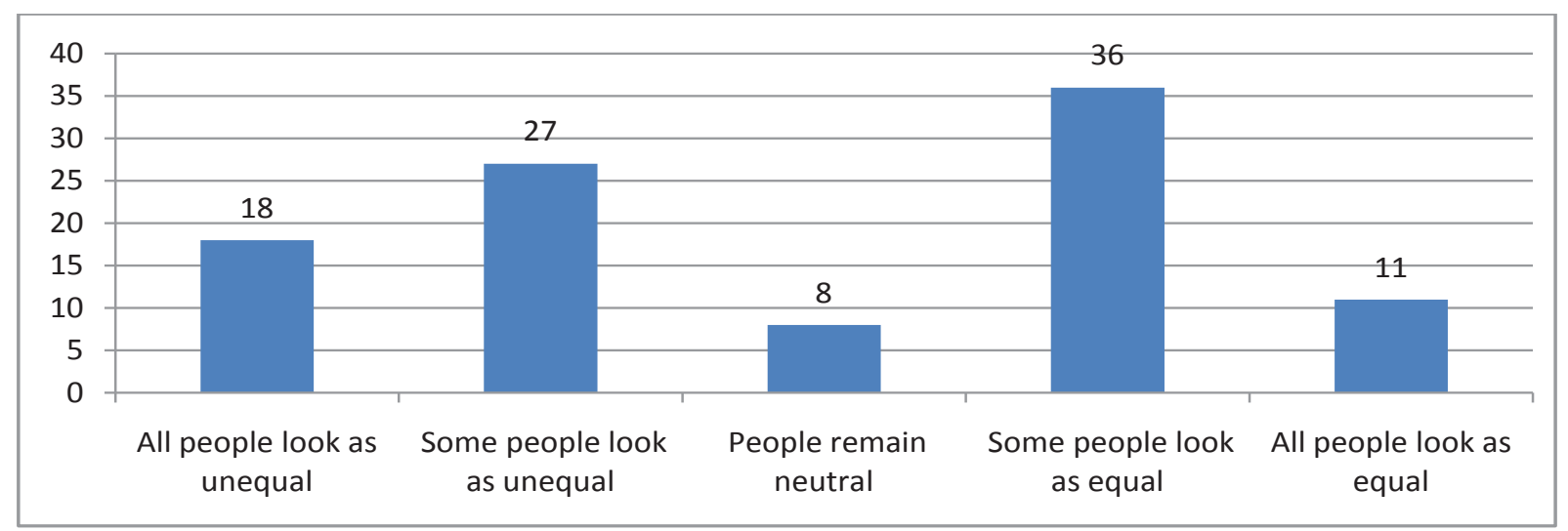

Fig. 1

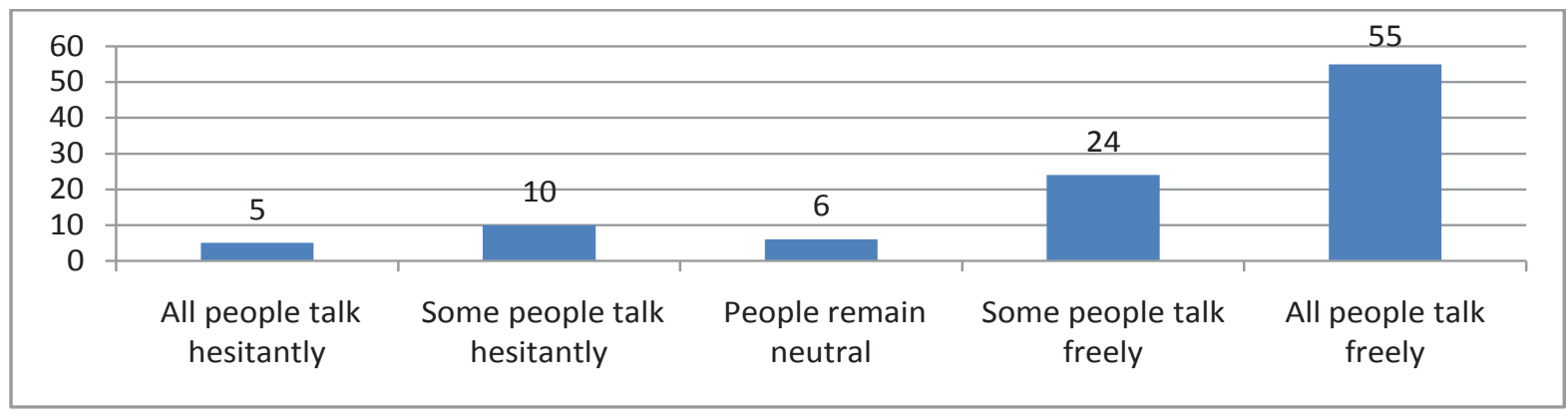

Fig. 2

interactions, 24 percent claimed that some people speak freely, and 55 percent claimed that everyone in their area speaks freely.

\section{Respect from other caste people in conversation}

They were also told to share their perceptions on respect or its absence they feel in communications. $15 \%$ of those polled feels that no one treats them with respect. Some people, according to $31 \%$ of respondents, do not treat others with respect. Individuals remain neutral during the interaction, according to $7 \%$ of respondents, $41 \%$ of respondents feels that some people give proper respect. $6 \%$ of respondents felt strongly about the respect they draw from every interaction of other caste.

\section{Quality Listening during interaction by other caste people}

Among the respondents, 5\% said that all members of other castes do not pay heed during a conversation.

$3 \%$ of respondents claimed that some people listen to them inappropriately, $2 \%$ claimed that people remain neutral, and 25\% indicated that some people listen with intent. The remaining $65 \%$ of respondents believed that everyone listens to them with full attention and intent.

\section{Relationship with other caste people}

According to this study, $13 \%$ of respondents believe that everyone has an unequal relationship. Some persons have an unequal relation, according to $21 \%$ of respondents. People remain neutral, according to $6 \%$ of respondents. Some people have an equal relationship, according to $38 \%$ of respondents, while all persons have a similar relationship, according to $23 \%$.

\section{Namashudra Home Visit by Other Caste Members}

$6 \%$ of Namashudra caste respondents said that people from other castes occasionally visit their 


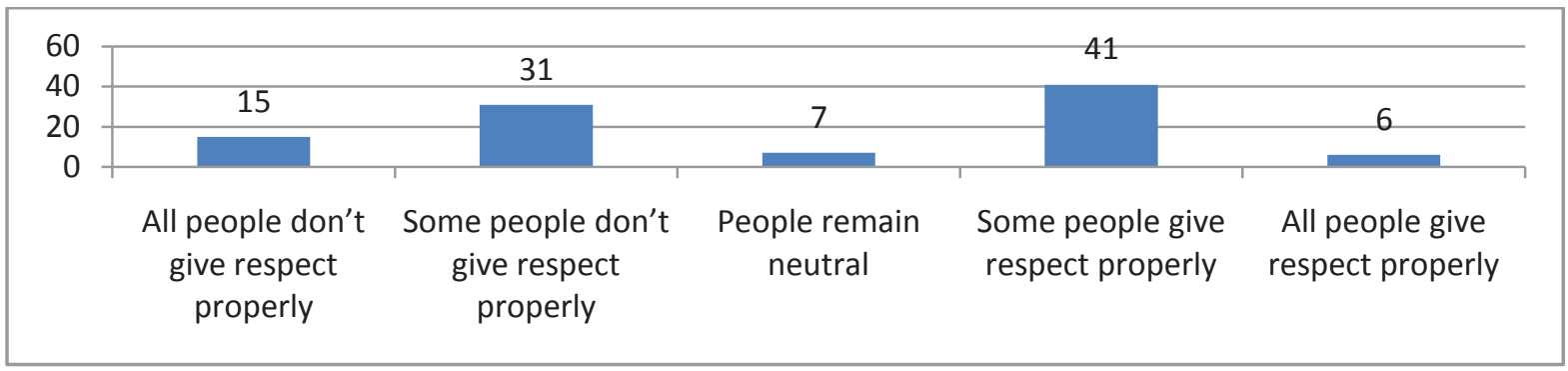

Fig. 3

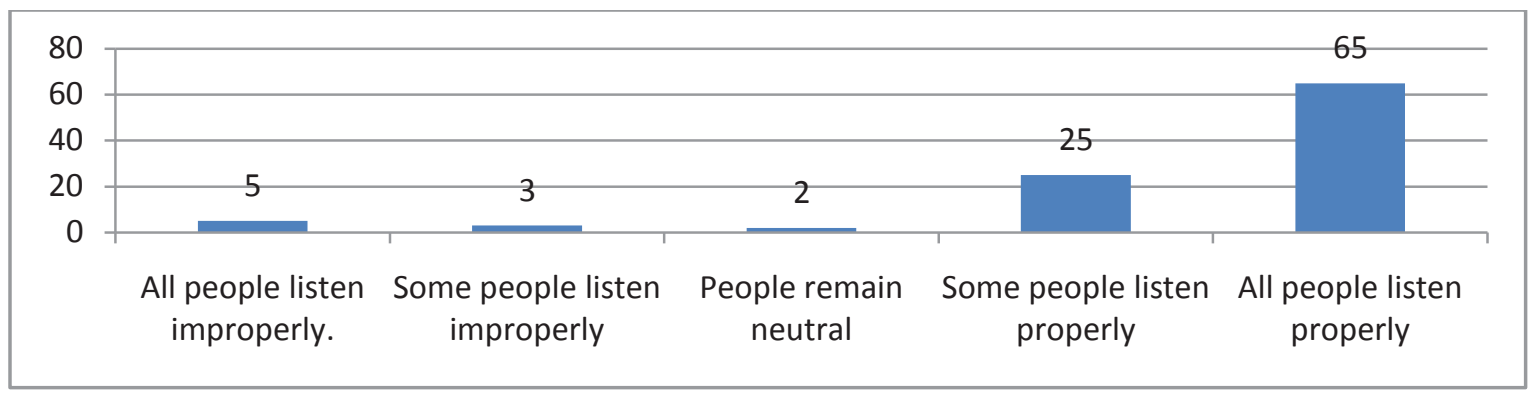

Fig. 4

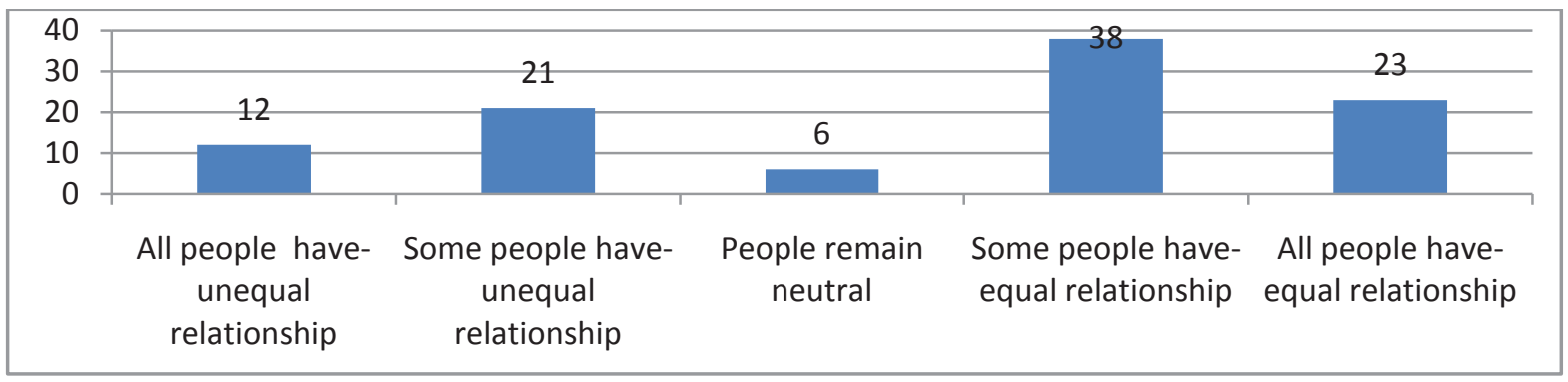

Fig. 5

homes. Some people visit their houses on occasion, according to $23 \%$ of respondents; individuals do not visit their houses, according to $11 \%$ of respondents; and some people visit their houses daily, according to $37 \%$ of respondents. The remaining $23 \%$ of respondents said that people from all castes come to their homes frequently.

\section{Inviting other caste people}

In this survey, $5 \%$ of respondents claimed that other castes are seldom invited to their homes. Some people are rarely welcomed to their homes on major holidays or celebrations, according to $9 \%$ of respondents. $6 \%$ of respondents stated that question of inviting does not arise, $24 \%$ said that some people are always invited to their homes on special occasions, and $56 \%$ stated that all persons from different castes in society are invited.

\section{Participation status in family occasions of other caste people}

$6 \%$ of Namashudra caste members said that other higher caste people participate as unequals in their family events. According to $18 \%$ of respondents, only some of them participate unequally; no one participate at all, according to $12 \%$ of respondents. Some other caste members participate equally, according to $29 \%$ of respondents, and all persons 
Inter-caste Communication Praxis of Namashudra Caste in West Bengal... 西形

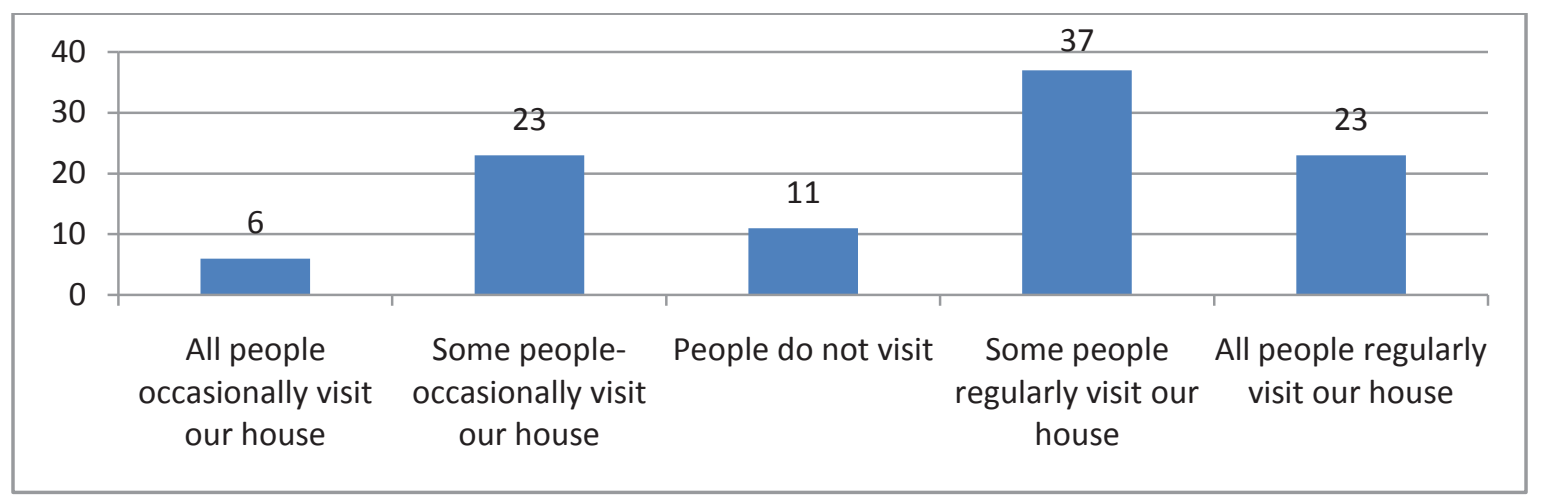

Fig. 6

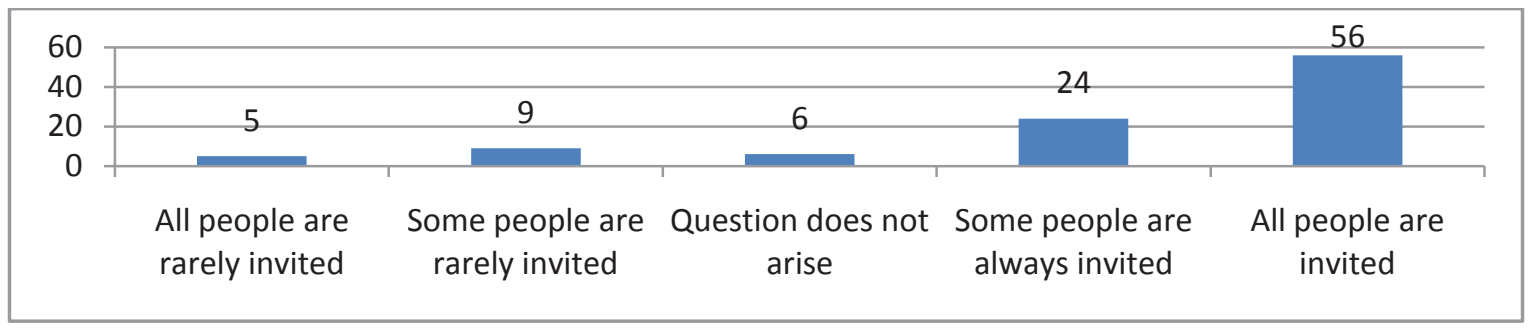

Fig. 7

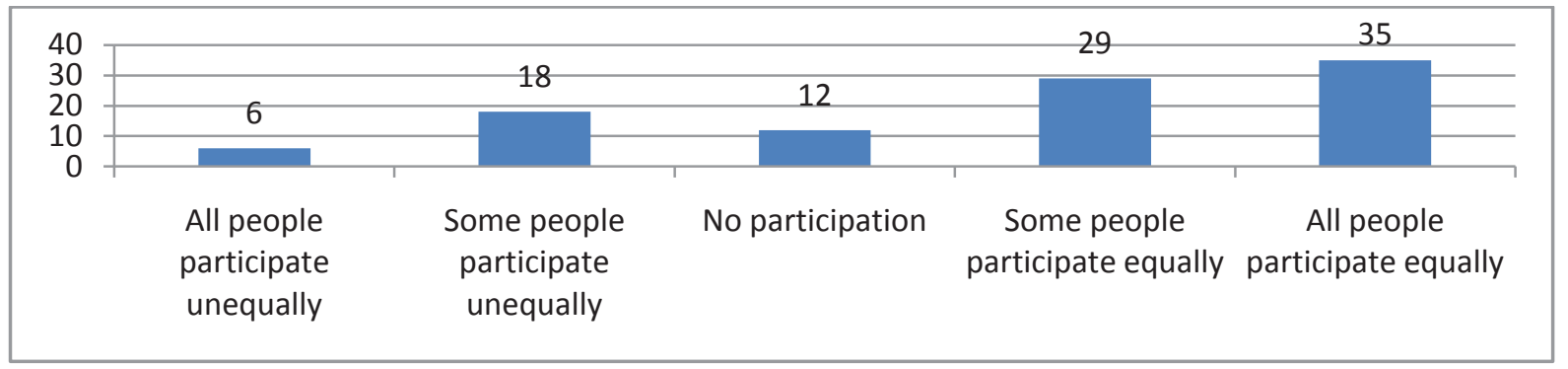

Fig. 8

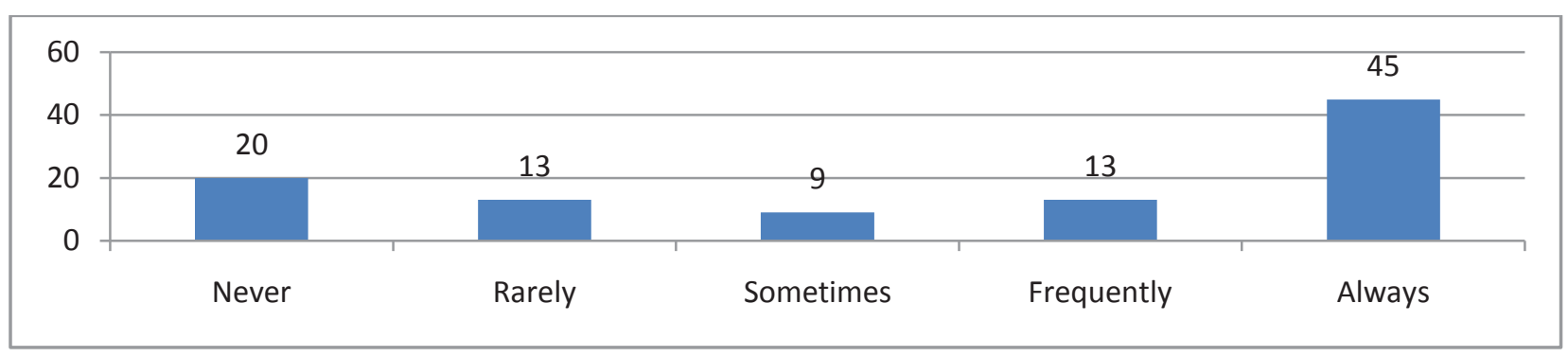

Fig. 9

participate equally on their occasions, according to $35 \%$ of respondents.

\section{Inter-caste sitting and dining}

In this study, $20 \%$ of respondents stated that people from different castes never sit with them or have food on special occasions. $13 \%$ of those polled said they only sit and eat once in a while. $9 \%$ of those polled admitted to taking a seat and eating food on occasion. $13 \%$ of those polled said they eat and 
sit frequently. The remaining $45 \%$ of respondents stated they always take a seat and eat.

\section{Analysis}

The study's main goal is to assess the nature of communication between caste groups from the perceptual frame of the Namashudras, traditionally considered as the last stratum of the caste hierarchy within the Varna structure in Bengal. It was considered that the caste phenomenon, which is believed to adversely affect lower caste groups more than higher caste groups, remains one of the major forces influencing social life.

The research focuses on the goal of caste communication, namely inter-caste communication and perception that creates and sustains such communication, whether tilted towards peaceful existence or conflict orientation.

Two emotion and feeling attributes of respect and treatment by other caste members offer consistent result. $47 \%$ asserts that they either draw respect from all other caste members or many; $47 \%$ feels that they are treated as similar or as equals.

On the other end of the scale, $15 \%$ felt no one from outside the caste respect them and 18\% felt that all treat them as unequal. However 31\% considered that only some did not respect while a close $27 \%$ considered that only some considered them unequal. Therefore, on emotional quotient, which mostly develops through education, experience, peer and family influence, around $3 / 4^{\text {th }}$ of the respondents are not in a perception of conflict with members of other castes.

Communicative action non-parametric variables which were chosen for understanding reality of conduct by both caste groups (Namashudra and Other) stated by the caste members give an interesting pattern. Sitting-dinning together, participation in Other's occasion, inviting others to Namashudra family occasion, Other's visiting Namashudra Home and relationship statements are indicative of presence or absence of inter-connect and inter-interest between Namashudras and Others. A positivity rate varying between $58 \%$ to $80 \%$ from sitting-dining to inviting Others' in family occasions byNamashudras shows that the peaceful togetherness is encouraging. Participation in Others' occasions is regularly practiced by Namashudra respondents while $60 \%$ Others visit Namashudra homes regularly.

Two non-parametric variables pertaining to quality of communication demonstrated through available modes of communicative action show positive indications. Intent and attention in listening, and frankness devoid of trepidation in conversation were taken as the most important qualities expressive of success in communication. While listening by Others has $90 \%$ positivity rate in five-point scale, Others' interaction quality was appreciated as free and frank by $79 \%$ Namashudras.

\section{DISCUSSION}

This study finds out that people from the region enjoy good inter-caste communication praxis. This is understood from the three aspects related to understanding communication phenomenon between Namashudras and other castes in two West Bengal neighbourhoods.

Both the areas have higher Namashudra caste population. In both areas, refugees from eastern part of Bengal, now Bangladesh and erstwhile East Pakistan have come year after year . People from different castes resided their for several decades and most of them have gone through same crisis of security and oppression on the other side of the border. They have to struggle for eking out a decent living for decades together. Some families could pull themselves up while others became helpless, living on doles and subsidies for subsistence living

In the above context, emotion and feeling about the other is understood from perception of the respondents. $3 / 4^{\text {th }}$ of them have positive emotionalorientation towards other castes. Communicative action component result supports the same and reflects its praxis. High level of quality of communication result proves that they have a nonconflict, inter-interested connect among members of the two communities, one rural and one urban.

Certainly, other factors in developing such a related existence therein requires further 
investigation. However, by connecting markers of relationship dynamism with communication as conscientious action, this study hints for further study to understand peace and conflict angles in communication at community level.

\section{REFERENCES}

Bandyopadhyay, S. 2004. “Caste, Culture And Hegemony: Social Domination In Colonial Bengal" Sage Publications, New Delhi, Thousand Oaks, London.

Dutta, N.K. 1931. Origin and Growth of Caste in India, The Book Company, Calcutta.

Choudhury, B.L. 2011. Indian Paradigm of Development: Man Standard and Communication. Kolkata: Sampark.

Choudhury, B.L. 2020. Peace-Education-Development: Decoding The Triad (2020), Editorial, IJPED, vol. 8, No. 1, June 2020.
Majumder, D.N. 1958. Caste and Communication in an Indian Village, Asia Publishing House, London.

Srinivas, M.N. 1977. 'Castes in Modern India and Other Essays, Asia Publishing House, Bombay.

Satyanarayana, A. 1993. Land, Caste and Dominance in Andhra Pradesh, Indian History Congress, Vol 54.

Sekhon, J. 2000. Modern India, Boston: McGraw-Hill.

Tanabe, A. 2006. Transformation of Inter-Caste Relationships in Post-Colonial Rural Orissa, Modern Asia Studies, Vol40, No-03, Cambridge University Press.

Weber, M. 1958. "The Religion of India: The Sociology of Hinduism and Buddhism," The Free Press, Glencoe, Illinois. 
